\title{
BMJ Open Quality Exploration of a quality improvement process to standardised preoperative tests for a surgical procedure to reduce waste
}

\author{
Rabia Shahid, ${ }^{1}$ Malone Chaya, ${ }^{2}$ Ian Lutz, ${ }^{3}$ Brian Taylor, ${ }^{2}$ Lily Xiao, ${ }^{4}$ Gary Groot ${ }^{5}$
}

To cite: Shahid R, Chaya M, Lutz I, et al. Exploration of a quality improvement process to standardised preoperative tests for a surgical procedure to reduce waste. BMJ Open Quality 2021;10:e001570. doi:10.1136/ bmjoq-2021-001570

- Additional supplemental material is published online only. To view, please visit the journal online (http://dx.doi.org/10. 1136/bmjoq-2021-001570).

Received 26 May 2021 Accepted 16 September 2021

D) Check for updates

(c) Author(s) (or their employer(s)) 2021. Re-use permitted under CC BY-NC. No commercial re-use. See rights and permissions. Published by BMJ.

${ }^{1}$ Department of Medicine, University of Saskatchewan, Saskatoon, Saskatchewan, Canada

${ }^{2}$ Department of Anesthesiology, University of Saskatchewan, Saskatoon, Saskatchewan, Canada

${ }^{3}$ Department of Orthopedic, University of Saskatchewan, Saskatoon, Saskatchewan,

Canada

${ }^{4}$ College of Medicine, University of Saskatchewan, Saskatoon,

Saskatchewan, Canada

${ }^{5}$ Community Health and

Epidemiology, University of

Saskatchewan, Saskatoon,

Saskatchewan, Canada

Correspondence to

Dr Rabia Shahid;

rabiakshahid@gmail.com

\section{ABSTRACT}

Background Preoperative tests are done to determine a patient's fitness for anaesthesia and surgery.

Local problem Although routine tests before surgery in the absence of specific clinical indications are not recommended, we observed high volumes of routine preoperative tests were performed in our institution. We describe a process to implement a standardised preoperative investigational approach to reduce unnecessary testing before surgeries.

Methods A series of six Plan-Do-Study-Act (PDSA) cycles was conducted for root cause analysis and process mapping, development of standardised tool (GRID), collection of baseline data, education and feedback, pilot testing and implementation and uptake of GRID. Root cause analysis revealed a lack of awareness of guidelines and a lack of a standardised tool to guide preoperative testing. We undertook a pilot quality improvement project to reduce unnecessary testing before knee and hip arthroplasty by developing and implementing a standardised tool (GRID) and engaging all stakeholders. Interventions A clinical development team (CDT) was formed, including all the stakeholders. Our CDT focused on a continuous rapid cycle improvement strategy.

Results After implementation of the tool in a subgroup of patients undergoing elective hip or knee arthroplasty, unnecessary coagulation tests (activated partial thromboplastin time and the international normalised ratio), electrolyte/renal panel tests and electrocardiograms were reduced by $81 \%(91 \%-17 \%), 81 \%(41 \%-7 \%)$ and $68 \%(35 \%-11 \%)$, respectively. No surgery was delayed or cancelled due to tests not performed before surgery.

Conclusions A standardised preoperative investigational approach based on patients' medical conditions rather than routine testing can reduce unnecessary tests before surgery. Further, implementing guidelines is more complex than developing guidelines. Hence, continuous PDSA cycles are essential to evaluate the processes in a quality improvement project. It can take time to build teams and have shared goals; however, once this is achieved, the success of a quality improvement project is certain.

\section{INTRODUCTION}

Problem

Several authorities, such as Choosing Wisely Canada (CWC) and the Canadian Society of Anesthesiology, recommend against unnecessary testing before surgery. They suggest performing tests based solely on an individual's history and medical conditions. ${ }^{1-8}$ Despite presence of such recommendations since several years, unnecessary tests continue to be performed before surgery. ${ }^{9}$ Our quality improvement team observed that unnecessary tests were being performed before surgeries in our centre as well. For example, we noticed that in every patient scheduled for an elective hip or knee replacement surgery, a complete blood count (CBC), electrolyte profile, urea and creatine levels (renal profile), coagulation tests (activated partial thromboplastin time (APTT) and the international normalised ratio (INR)) and electrocardiogram (EKG) were routinely requested preoperatively, regardless of the patient's clinical status.

Saskatoon City Hospital (SCH) is the primary centre for elective hip and knee replacement surgeries in Saskatoon, Saskatchewan. A total of 686 elective hip procedures (total hip arthroplasty, n=311) and 1685 elective knee procedures (total knee arthroplasty, $\mathrm{n}=915$ ) were performed in the year before this project began.

\section{BACKGROUND}

Preoperative tests, along with history and physical examination, determine patients' fitness for anaesthesia and surgery. Preoperative tests in an asymptomatic individual do not predict complications. ${ }^{9-11}$ Routine preoperative tests are defined as those done in the absence of any specific clinical indication or purpose; they are conducted in all patients undergoing a given procedure, regardless of their medical history or other clinical features. ${ }^{12-17}$ Tests are unnecessary when they do not contribute to the care or positive clinical outcomes in a patient before or after surgery. Currently, several medical authorities discourage extensive, non-selective routine 
testing in patients undergoing elective surgeries. Instead, tests are recommended based on the patients' medical comorbidities. $^{3} 12$

According to the Canadian Institute for Health Information, 62000 hip replacements and 75000 knee replacements were performed in Canada in 2018-2019; a total of more than 1.4 billion dollars were spent on these surgeries. ${ }^{18}$ Given the significant number of procedures performed every year, unnecessary testing may significantly burden the patients, both physically and emotionally. In addition, it may strain financial, human and operational resources within provincial health systems. Also, unnecessary testing may result in the postponement of a surgery that could affect the health of a patient and their quality of life. Furthermore, unnecessary testing in an asymptomatic individual can cause falsepositive results. False-positive results can lead to a battery of further unnecessary tests and consultations, which can result in a delay of surgery and additional cost to the system. ${ }^{19}$

\section{METHODS}

This pilot quality improvement project aimed to reduce unnecessary preoperative testing by $50 \%$ in patients undergoing hip or knee surgery at the SCH by August 2017. For this, we started engaging all stakeholders. An interdisciplinary collaboration involving anesthesiologists, orthopaedic surgeons, internists, patient representative, nursing staff and manager of the preassessment clinic (PAC) was developed. A series of Plan-Do-Study-Act (PDSA) cycles was conducted.

\section{PDSA cycle 1: root cause analysis and process mapping}

Initial meetings were held with the quality improvement team. Root cause analysis was conducted using a fishbone diagram. The reasons for unnecessary testing, such as (1) lack of communication among the consultants involved in the care of the patient, both before and after surgery, ${ }^{20}$ (2) assumption that the other specialty would require the test, (3) lack of awareness regarding current recommendations, (4) the practice of traditions, (5) lack of a standardised protocol for testing before surgery and (6) concerns about delay or cancellation of surgery, were discussed. ${ }^{21}$ We observed that besides the lacking awareness of guidelines, the lack of a standardised tool for preoperative testing resulted in unnecessary testing. Education alone is not effective in quality improvement; rather, interventions are required to introduce system level changes with the involvement of all the stakeholders.

When we performed process mapping, we observed that most of the testing was happening in the PAC at SCH. PAC is a clinic where patients are assessed days or weeks before surgery by a nurse, physiotherapist or consultants (internal medicine or anaesthesia), if needed.

\section{PDSA cycle 2: development of standard GRID}

The clinical development team (CDT), including an internal medicine physician, orthopaedic surgeon, anesthesiologists, manager of PAC and patient representative, was formed. Based on the CWC guidelines and the consensus of CDT, a standard GRID to guide testing, tailored to the patient's medical conditions, was developed (online supplemental appendix 1). Standard GRID is a tool devised to help the clinician decide on tests based on the patient's clinical status. As per consensus within the quality improvement team and based on guidelines, CBC was performed for all patients; however, tests for electrolytes/renal profile and APTT, INR and EKGs were recommended according to patients' medical condition and medication history. The clinical development team met regularly to discuss the progress of the work. Ideas were shared to engage other stakeholders. Physician members of the CDT engaged other physicians in their respective departments by informing them of this project in the department rounds and also by communicating to the internal medicine and anaesthesiologist who were assigned for the week. Manager of PAC held educational rounds with nurses in the PAC. A patient representative attended most of the meetings and provided great insight from her own experience with a surgery.

\section{PDSA cycle 3: baseline data}

For evaluating the magnitude of the problem and the number of unnecessary tests, the baseline chart was reviewed for 6 weeks. Baseline data were compared using standard GRID that was developed in PDSA cycle 2. A total of 256 patients, scheduled for total hip and knee arthroplasties, were reviewed. Of which, $157(61.3 \%)$ patients were female and $99(38.7 \%)$ were male. Mean age $( \pm$ SD) was 66.06 years $(10 \pm 10.7) ; 7.8 \%, 52 \%$ and $39.8 \%$ of the patients were of the age $\leq 50$ years, 51-69 years and $\geq 70$ years, respectively. The proportion of the patients who underwent total hip arthroplasty, total knee arthroplasty and bilateral knee arthroplasty were $39.8 \%, 57.8 \%$ and $2.3 \%$, respectively. Baseline data were assessed based on the standardised GRID. A baseline chart review $(n=256)$ in patients undergoing elective knee or hip arthroplasty at $\mathrm{SCH}$ revealed that $91 \%$ of the patients had no indication for APTT and INR, $41 \%$ for electrolytes and renal profile and $35 \%$ for an EKG.

\section{PDSA cycle 4: education and feedback}

Multiple meetings were held with the staff at the PAC. In the PAC, registered nurse (RN) took the history of the patient and filled out the GIRD. After the GRID was filled out by RN, it was signed by a physician. The nursing staff at the PAC was educated in this regard. An educational round to discuss the rational behind standardised testing was organised with the department of anaesthesia. There were concerns regarding the delay or cancellation of surgery because of the non-performance of the required tests. Therefore, we decided to do a pilot project involving a small subset of patients, to alleviate (or address) this concern. 
PDSA cycle 5: pilot testing/implementation of GRID

A standardised GRID was implemented in the PAC at the SCH. Patients scheduled for elective hip and knee replacement were assessed in the PAC for preoperative optimisation. After consulting all stakeholders, we arrived at the opinion that using a standardised GRID in the PAC would have the most impact on reducing unnecessary tests as the blood work was usually done in the PAC.

A pilot quality improvement project was implemented among patients undergoing elective hip and knee joint replacement surgery. A standardised GRID was used to determine the preoperative tests to be performed. After the implementation, testing was performed based on the patient's detailed history and medical condition. A nurse took the history and filled the GRID to be signed by one of the consultant physicians (internal medicine or anaesthesiologist). Tests were performed as per the patient's medical condition and medication history. A patient representative was involved and attended most of the meeting to provide input.

\section{PDSA cycle 6: uptake of the GRID}

After the implementation of GRID, its uptake was assessed. The GRID was used to order tests only for $33 \%$ of the patients in week 1 and $44 \%$ of the patients in week 2. Further meetings were conducted with the PAC staff; the consultants working at the PAC were reminded regarding the implementation of the GRID via phone calls. In week 3, the uptake of the GRID had increased to $92 \%$.

A

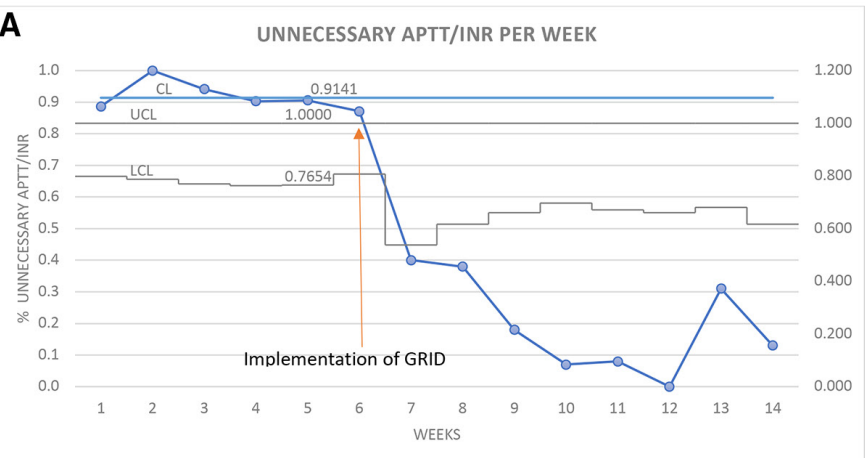

B

UNNECESSARY RENAL PANEL AND ELECTROLYTES/ PER WEEK

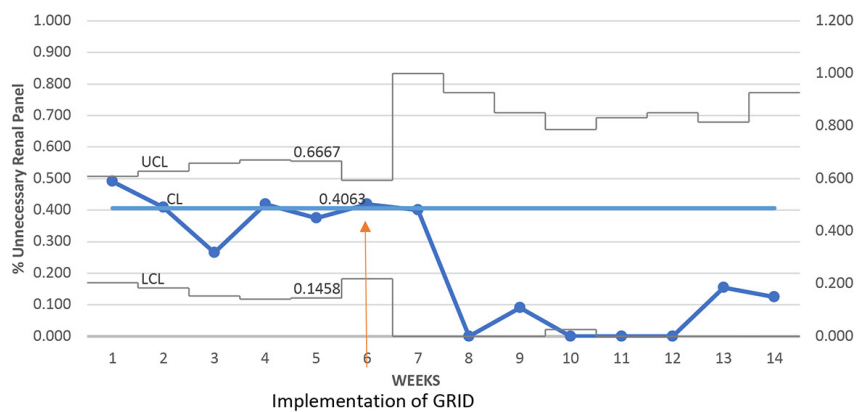

\section{Measures}

Outcome measure: Percentage of unnecessary preoperative tests per week.

Process measure: Number of the patients requiring additional tests on the day of the surgery.

Balance measure: Cancellation or delay in the surgery due to the non-performance of the required tests before surgery.

\section{RESULTS}

Our primary outcome was the percentage of unnecessary tests per week. We evaluated patients for a total of 14 weeks; weeks 1-6 were considered as the preimplementation phase and 7-14 as the postimplementation phase. The postimplementation data were collected for 8 weeks $(n=83)$. Here, we only included patients when the GRID was used to guide tests in the analysis since we aimed to assess the effectiveness of GRID to reduce unnecessary testing. In the postimplementation phase, the GRID was applied on 83/109 (76\%) patients. Overall, 14/83 (16.86\%) APTT/INR, 9/79 (11.39\%) EKG and 6/83 $(7.22 \%)$ renal profile did not have any indication. Data on three patients were not complete to assess if EKG was indicated or not. Shewhart p-charts were employed to plot the percentage of unnecessary tests per week (figure 1). We observed a downward trend in the number of unnecessary tests on the application of GRID. The unnecessary APTT/INRs, electrolyte/renal profiles and EKGs were reduced by $81 \%$ (91\% to $17 \%), 81 \%(41 \%$ to $7 \%)$ and $68 \%$ ( $35 \%$ to $11 \%$ ), respectively, after the implantation

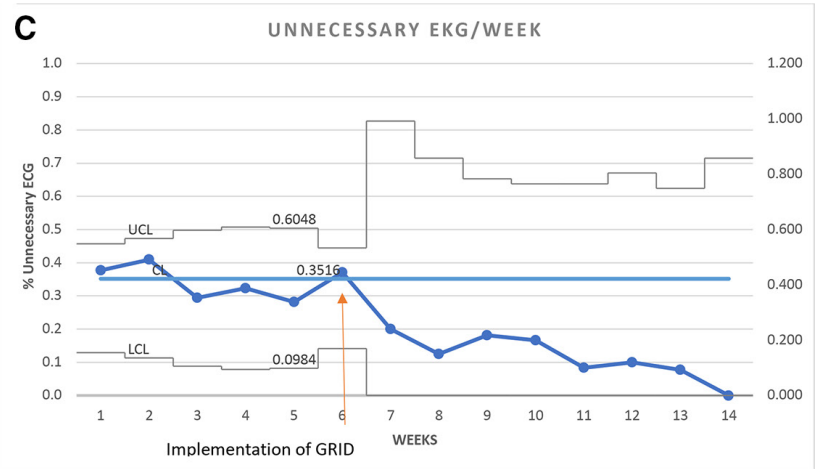


of GRID. Five tests that were indicated but not done in the PAC were performed on the day of surgery. To our knowledge, no surgery was delayed or cancelled because of the non-performance of required tests before surgery.

\section{Lessons and limitations}

The physicians' education, involvement of stakeholders and engagement of the front-line staff made implementation of this prospective pilot quality improvement project easier and effective. Regular monthly meetings ensured regular review of the process. Our meetings were held in person, which made regular attendance challenging for some stakeholders; use of virtual platform might have been more helpful.

This project was piloted on a small group of patients to test a new process. After this pilot project, we met all members of the orthopaedic department at their monthly meetings. After showing the success and data from this project, we were able to successfully engage other surgeons and this protocol was implemented for all elective hip and knee arthroplasty procedures in SCH. Data collection is being done until 1 year after the implementation. Currently, it is being rolled out in other surgeries and GRID is being used daily at PAC in SCH.

Educational outcomes of PDSA cycle was not measured and would have been useful. Another limitation was that we examined tests that were done in the SCH (either preoperatively at the PAC or on the day of surgery); therefore, we could not account for the tests that were done outside the SCH. Although, based on our experience, we believe that the probability of that was very small.

\section{CONCLUSIONS}

Implementing guidelines is more complex than developing guidelines. ${ }^{22}$ Having evidence does not mean it is used in clinical practice. ${ }^{23}$ Designing a tool does not necessarily mean it will be used in clinical practice. Furthermore, if a tool has been used, it does not mean that it is being used accurately. Hence, continuous PDSA cycles are important for evaluating whether the tool in place is used and used correctly and consistently. Education alone, without the application of standardised GRID, would not have been effective. ${ }^{24}$ It takes time to develop teams and have shared goals. However, once organised, teamwork can have a substantial effect on the progression of a quality improvement project. Unnecessary preoperative tests can impose a significant burden on patients and the healthcare system. However, this can be mitigated by the implementation of a standardised tool with the involvement of all the stakeholders.

Identifying the root causes of the problem and assessment of the perioperative process were the initial steps in identifying areas of improvement. This led to the development of a standard tool, reflecting major guidelines, to reduce waste without reducing the quality of care. The baseline data obtained, using the standard GRID, confirmed a high number of unnecessary testing. This was an important step for facilitating education, engagement and change management. Communication, open exchange of information, education and feedback prior to implementation of GRID facilitated cooperation and a collaborative environment and were key for successful pilot testing. Furthermore, an initial small-scale implementation with focus on small group of patients was helpful to assess feasibility of this project on a larger scale. Lastly, assessment and evaluation of the project were key steps to determine success and challenges and viability of full-scale implementation.

Acknowledgements The authors would like to thank Jennifer Link, manager of Pre-Assessment Clinic at Saskatoon City Hospital, for her support for the implementation of this project: Appropriateness of Care team, Health Quality Council, Saskatchewan. This project was completed as a part of Clinical Quality Improvement Program by Health Quality Council, Saskatchewan. It was sponsored by Clinical Quality Improvement Program.

Contributors RS provided the concept and design, drafted the article, revised it for necessary content and provided final approval for submitting the manuscript. GG contributed to necessary revisions of the article and offered supervision. GG, MC, $\mathrm{IL}$ and BT were involved in the concept and implementation of the project. LX was involved in the data collection in the preimplementation phase.

Funding The authors have not declared a specific grant for this research from any funding agency in the public, commercial or not-for-profit sectors.

Competing interests None declared.

Patient consent for publication Not required.

Ethics approval Being a quality improvement project, it was exempt from the requirement of University of Saskatchewan Research Ethics Board.

Provenance and peer review Not commissioned; externally peer reviewed.

Data availability statement All data relevant to the study are included in the article.

Supplemental material This content has been supplied by the author(s). It has not been vetted by BMJ Publishing Group Limited (BMJ) and may not have been peer-reviewed. Any opinions or recommendations discussed are solely those of the author(s) and are not endorsed by BMJ. BMJ disclaims all liability and responsibility arising from any reliance placed on the content. Where the content includes any translated material, BMJ does not warrant the accuracy and reliability of the translations (including but not limited to local regulations, clinical guidelines, terminology, drug names and drug dosages), and is not responsible for any error and/or omissions arising from translation and adaptation or otherwise.

Open access This is an open access article distributed in accordance with the Creative Commons Attribution Non Commercial (CC BY-NC 4.0) license, which permits others to distribute, remix, adapt, build upon this work non-commercially, and license their derivative works on different terms, provided the original work is properly cited, appropriate credit is given, any changes made indicated, and the use is non-commercial. See: http://creativecommons.org/licenses/by-nc/4.0/.

\section{REFERENCES}

1 Drop the Pre-Op. Available: https://choosingwiselycanada.org/ perspective/preop-toolkit

2 Merchant R, Chartrand D, Dain S, et al. Guidelines to the Practice of Anesthesia - Revised Edition 2016. Can J Anaesth 2016;63:86-112.

3 Dobson G, Chong M, Chow L, et al. Guidelines to the Practice of Anesthesia - Revised Edition 2018. Can J Anaesth 2018;65:76-104.

4 Fritsch G, Flamm M, Hepner DL, et al. Abnormal pre-operative tests, pathologic findings of medical history, and their predictive value for perioperative complications. Acta Anaesthesiol Scand 2012;56:339-50.

5 Onuoha OC, Arkoosh VA, Fleisher LA. Choosing wisely in anesthesiology: the gap between evidence and practice. JAMA Intern Med 2014;174:1391-5.

6 Martin SK, Cifu AS. Routine preoperative laboratory tests for elective surgery. JAMA 2017;318:567-8. 
7 Czoski-Murray C, Lloyd Jones M, McCabe C, et al. What is the value of routinely testing full blood count, electrolytes and urea, and pulmonary function tests before elective surgery in patients with no apparent clinical indication and in subgroups of patients with common comorbidities: a systematic review of the clinical and costeffective literature. Health Technol Assess 2012;16:1-159.

8 De Hert S, Imberger G, Carlisle J. Andrew the task force on preoperative evaluation of the adult noncardiac surgery patient of the European Society of Anaesthesiology preoperative evaluation of the adult patient undergoing non-cardiac surgery. Eur $J$ Anaesthesiol 2011;28:684-722.

9 Sigmund AE, Stevens ER, Blitz JD, et al. Use of preoperative testing and physicians' response to professional Society guidance. JAMA Intern Med 2015;175:1352-9.

10 Dzankic S, Pastor D, Gonzalez C, et al. The prevalence and predictive value of abnormal preoperative laboratory tests in elderly surgical patients. Anesth Analg 2001;93:301-8.

11 Liu LL, Dzankic S, Leung JM. Preoperative electrocardiogram abnormalities do not predict postoperative cardiac complications in geriatric surgical patients. J Am Geriatr Soc 2002;50:1186-91.

12 Fleisher LA, Fleischmann KE, Auerbach AD, et al. 2014 ACC/ AHA guideline on perioperative cardiovascular evaluation and management of patients undergoing noncardiac surgery: a report of the American College of Cardiology/American heart association Task force on practice guidelines. J Am Coll Cardiol 2014;64:e77-137.

13 Kumar A, Srivastava U. Role of routine laboratory investigations in preoperative evaluation. J Anaesthesiol Clin Pharmacol 2011;27:174-9.

14 Committee on Standards and Practice Parameters, Apfelbaum JL, Connis RT, et al. Practice Advisory for preanesthesia evaluation: an updated report by the American Society of Anesthesiologists Task force on Preanesthesia evaluation. Anesthesiology 2012;116:522-38.
15 Feely MA, Collins CS, Daniels PR, et al. Preoperative testing before noncardiac surgery: guidelines and recommendations. Am Fam Physician 2013;87:414-8.

16 Health Quality Ontario. Preoperative testing in asymptomatic patients undergoing Lowor intermediate-risk noncardiac surgery: a scoping review. Available: http://www.hqontario.ca/Portals/0/Documents/ evidence/cwc/report-cwc-preop-testing-noncardiac-surgery-1606en.pdf

17 Johansson T, Fritsch G, Flamm M, et al. Effectiveness of non-cardiac preoperative testing in non-cardiac elective surgery: a systematic review. Br J Anaesth 2013;110:926-39.

$18 \mathrm{CIHI}$. Hip and knee replacements inCanada: CJRR annual StatisticsSummary, 2018-2019. Available: https://www.cihi.ca/sites/ default/files/document/cjrr-annual-statistics-hip-knee-2018-2019report-en.pdf

19 Hepner DL. The role of testing in the preoperative evaluation. Cleve Clin J Med 2009;76 Suppl 4:S22-7.

20 Good Stewardship Working Group. The "top 5" lists in primary care: meeting the responsibility of professionalism. Arch Intern Med 2011;171:1385-90.

21 Brown SR, Brown J. Why do physicians order unnecessary preoperative tests? A qualitative study. Fam Med 2011;43:338-43.

22 Field MJ, Lohr KN, Institute of Medicine (US) Committee on Clinical Practice Guidelines. Guidelines for Clinical Practice: From Development to Use. In: Implementing guidelines: overview and illustrative cases. 3. Washington (DC: National Academies Press (US) 1992. https://www.ncbi.nlm.nih.gov/books/NBK234499/

23 Soong C, Shojania KG. Education as a low-value improvement intervention: often necessary but rarely sufficient. BMJ Qual Saf 2020;29:353-7.

24 Morris ZS, Wooding S, Grant J. The answer is 17 years, what is the question: understanding time lags in translational research. $J R$ Soc Med 2011;104:510-20. 